\title{
Periodistas que ejercen de documentalistas (¿y viceversa?). Nuevas relaciones entre la redacción y el archivo tras la digitalización de los medios
}

\author{
Por Josep-Lluís Micó-Sanz, Pere Masip-Masip y José-Alberto García-Avilés
}

\begin{abstract}
Resumen: La digitalización de los archivos de los medios de comunicación ha permitido mejorar tanto el trabajo de los documentalistas como el de los periodistas. Sin embargo, un porcentaje notable de redactores españoles prefiere buscar información en internet antes que en los nuevos servicios de documentación. El hecho de que muy pocos periodistas cuenten con la formación adecuada para la recuperación de datos es la causa de que la calidad de sus producciones vaya en descenso. Nuestra investigación se basa en la observación y en más de 70 entrevistas a profesionales de diversas redacciones entre 2001 y 2006, y en una encuesta entre los responsables de los centros de documentación de las televisiones y los periódicos más relevantes del país en 2008.
\end{abstract}

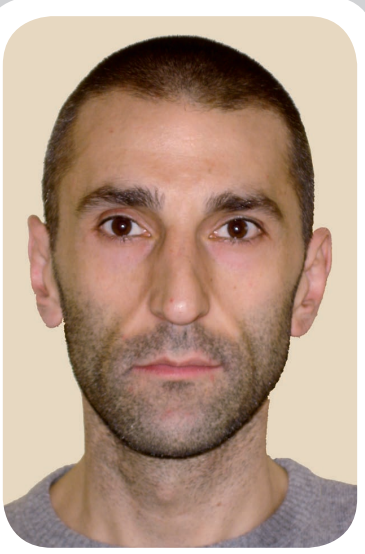

Josep-Lluís Micó-Sanz es periodista y codirector del grupo de investigación Digilab, Laboratori de Comunicació Digital de la Facultat de Comunicació Blanquerna de la Universitat Ramon Llull. Es doctor por la Universidad Politécnica de Valencia y licenciado en ciencias de la información por el CEU San Pablo. Ha publicado diversos libros y capítulos en obras colectivas sobre la digitalización de los medios de comunicación y los nuevos perfiles profesionales en el sector de la información.

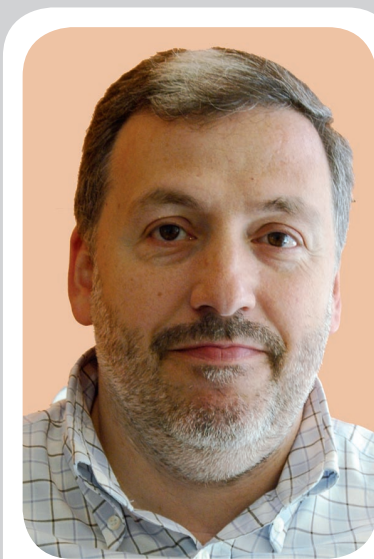

Pere Masip-Masip es doctor en periodismo por la Universitat Ramon Llull, licenciado en geografía e historia y diplomado en biblioteconomía y documentación por la Universitat de Barcelona. Es profesor de la Facultat de Comunicació Blanquerna y codirector del grupo de investigación Digilab de la misma universidad. Forma parte de grupos de investigación sobre cibermedios en colaboración con investigadores de Brasil y sobre convergencia digital en medios de comunicación.

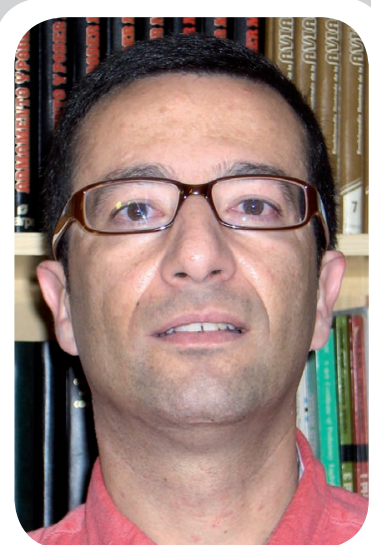

José-Alberto García-Avilés es profesor de la titulación de periodismo en la Universidad Miguel Hernández de Elche. Es Bachelor of Arts por la Universidad Nacional de Irlanda, licenciado en periodismo y doctor en comunicación por la Universidad de Navarra. Ha ejercido el periodismo en varios canales de TV y en la productora Euroview. Participa en una investigación sobre la convergencia de medios en España y sobre convergencia de redacciones en Europa.

Palabras clave: Centros de documentación, Prácticas profesionales, Periodismo, Prensa, Televisión, Digitalización, Perfiles profesionales.

Title: Journalists as news librarians (and viceversa?). New relationships between newsroom and archive after media digitization.

Abstract: Digitization of media archives has improved both news librarians' and journalists'work. However, a significant proportion of Spanish journalists prefer searching for information on the Internet rather than in archives. Moreover, the quality of journalists' work decreases because few journalists receive proper training on information retrieval. Our research is based on ethnographic observation and interviews with more than 70 professionals from several newsrooms carried out between 2001 and 2006, complemented by a survey of the heads of archives at the main channels and newspapers.

Keywords: Archives, Professional practices, Journalism, Press, Television, Digitization, Professional profiles.

Micó-Sanz, Josep-Lluís; Masip-Masip, Pere; García-Avilés, José-Alberto. "Periodistas que ejercen de documentalistas (¿y viceversa?). Nuevas relaciones entre la redacción y el archivo tras la digitalización de los medios". El profesional de la información, 2009, mayo-junio, v. 18, n. 3, pp. 284-290.

DOI: 10.3145/epi.2009.may.05

\section{Digitalización de las redacciones y nuevos perfiles profesionales}

La introducción de cualquier tecnología contribuye a la transformación de las prácticas periodísticas, al establecimiento de otras nuevas y al desarrollo de nuevas habilidades. Así, gracias a la introducción de la tecnología digital y los sistemas de edición no lineal, los periodistas de televisión han debido asumir tareas que 
hasta el momento eran desempeñadas por trabajadores especializados como operadores de cámara, montadores o técnicos de sonido. Gracias fundamentalmente a internet aunque no exclusivamente, los periodistas han adquirido mayor protagonismo en los procesos de búsqueda y recuperación de la información, llegando a modificar sus rutinas y su relación con los documentalistas.

La digitalización abre nuevas perspectivas en el análisis de las competencias profesionales en los medios. En este contexto, numerosas empresas implantan algún tipo de convergencia para crear un marco común: la redacción multimedia, una factoría informativa que centraliza mensajes, gestiona asignaciones y canaliza flujos de trabajo para editar las versiones impresas, audiovisuales y en línea de contenidos cada vez más personalizados (García-Avilés, 2006). Del mismo modo, la convergencia y los nuevos perfiles acarrean la desaparición o mutación de ciertos roles profesionales. Rintala y Suolanen (2005) a partir de una investigación llevada a cabo en Finlandia entre 2001 y 2002 sintetizan estas transformaciones del siguiente modo:

\section{"Los periodistas han adquirido mayor protagonismo en la búsqueda y recuperación de la información, llegando a modificar sus rutinas y su relación con los documentalistas"}

- Transferencia de tareas: las funciones que antes llevaba a cabo un profesional determinado, ahora las asume otro.

- Fusión de tareas: ciertas actividades que en el pasado eran competencia de dos o más profesionales, ahora son ejecutadas sólo por uno.

- Incremento de tareas: los nuevos medios generan un mayor número de tareas para el periodista, por la necesidad de intervenir en todas las fases del proceso (desde la documentación hasta gestionar los comentarios de los lectores) o por la exigencia de elaborar una misma información para diferentes plataformas.

La digitalización ha afectado en distinto grado a todos los actores de los medios y, por lo tanto, también a los documentalistas y los servicios de documentación. Es el caso de las transformaciones de los archivos de televisión en España, como argumentan López-deQuintana, Agirreazaldegi y De-Bustos (2007) en sendos artículos publicados en El profesional de la información. La digitalización y la creación de bases de datos trajeron consigo importantes consecuencias. El tradicional papel de intermediario de los documentalistas entra en crisis cuando los redactores tienen acceso desde sus ordenadores a los fondos digitales del medio, así como a las bases de datos comerciales (Paul, 1997). Desde finales de los 90, las interfaces son más intuitivas, los costes de conexión disminuyen y aparece internet. Todo ello contribuye a que los periodistas ganen autonomía y los redactores adopten algunas de las tareas clásicas de los documentalistas, lo que, para Giménez (2002), "no es más que un reajuste de funciones dentro de cada profesión".

Los archivos digitales hacen posible una mejor conservación de los fondos y garantizan la versatilidad y la facilidad en el manejo de la información. El periodista audiovisual participa en prácticamente todo el proceso de producción: la ingesta del material, la redacción de la pieza, la edición del vídeo, la emisión del programa... El cambio no sólo afecta a los redactores, también a los documentalistas, los operadores de vídeo, los realizadores, los productores, etc. Con las nuevas herramientas, se gana en inmediatez y se mejora la documentación de los contenidos (García-Avilés; León, 2002). Y es que el archivo ya no puede separarse del resto de las fases que integran el ciclo de producción (Hidalgo, 2005; Risoto, 2004). Gracias a ello, la documentación en las redacciones multimedia se convierte en un valor añadido que sitúa favorablemente a los medios respecto a su competencia (Rubio, 2005).

Como consecuencia, se subraya la necesidad de "redefinir el papel del documentalista en el entorno multimedia, una vez que los usuarios han ganado autonomía en la recuperación y la introducción de información se ha universalizado dentro de la empresa" (Martín; López, 1999). Por este motivo, los mismos autores defienden "un plan de formación específico para estos 'nuevos documentalistas', que incida en la polivalencia”. Según Paul, los documentalistas deben asumir un nuevo papel: el de consultores, consejeros y formadores de los periodistas. En esta línea, Rubio-Lacoba (2004) insiste en que los documentalistas deben cumplir una función gestora, no suministradora. Deberían anticiparse a los requerimientos de los periodistas y satisfacer solicitudes complejas fuera de las competencias de los redactores y forjar una nueva asociación informativa con la redacción (2005). Trillo y Moya-Anegón argumentan que se están convirtiendo en "gestores de contenidos" (2008).

\section{Objetivos y metodología}

Este artículo forma parte de una investigación más amplia sobre la incidencia de la digitalización en la profesión periodística llevada a cabo por los autores desde hace años (Masip, 2008; Micó, 2006; García- 
Avilés, 2006; Masip, 2005; Micó, 2003). En concreto, se ahonda en el análisis de cómo los periodistas asumen tareas tradicionalmente desempeñadas por los documentalistas y las nuevas relaciones que surgen entre ambos.

Los resultados proceden del trabajo de campo en diversas redacciones realizado entre 2001 y 2006, y de entrevistas mantenidas con más de 70 profesionales, que se complementaron con una encuesta durante el primer semestre de 2008 a los responsables de los centros de documentación de las televisiones y periódicos más relevantes del país.

En concreto, se escogieron los cinco canales generalistas de carácter nacional (Televisión Española, Antena 3, Telecinco, Cuatro y La Sexta) y las cadenas autonómicas de la Federación de Organismos de Radio y Televisión Autonómicos (Forta). En cuanto a los medios impresos, se eligieron los 18 periódicos de mayor tirada, según los datos de la Oficina de Justificación de la Difusión: El país, El mundo, $A B C$, La vanguardia, El periódico de Catalunya, La verdad, Diario de Navarra, El correo, La voz de Galicia, Heraldo de Aragón, La razón, Avui, Ideal, Hoy, La voz de Asturias, Diario de Mallorca, Canarias 7 y El norte de Castilla. En total, la muestra abarcó 35 medios, aunque finalmente se redujo a 33 debido a que fue imposible contactar con el responsable de un periódico y otra de las empresas no disponía de centro de documentación. Se obtuvieron respuestas de 25 medios, lo que supone un $76 \%$ del total. No se aprecian diferencias significativas en función de los medios: las televisiones representan el $77 \%$ de los cuestionarios retornados y los periódicos, el $75 \%$.

\section{La digitalización de los centros de documentación}

\subsection{Archivos audiovisuales: un refuerzo útil}

A la luz de los resultados obtenidos, se observa un panorama contradictorio en cuanto al papel de los documentalistas y su relación con los periodistas. Mientras que los archivos audiovisuales se han visto reforzados gracias a la digitalización, los de documentación impresa atraviesan una situación paradójica.

La decisión acerca del material que pasa a engrosar el archivo de la redacción, los procedimientos de acceso y su uso posterior, constituyen las cuestiones esenciales en la gestión de contenidos. De acuerdo con el director técnico de Telecinco, José-Luis Romero ${ }^{1}$, los nuevos sistemas son extremadamente versátiles: "Para acceder a imágenes del archivo, el periodista ya no depende de nadie, sólo de sí mismo. Desde su propio terminal accede a la información del archivo, a ficheros de baja velocidad; selecciona, marca y formula su petición. $\mathrm{La}$ información le llega a su servidor y puede seguir trabajando. Es decir, que lo busca en una base de datos, lo relaciona y lo solicita, lo revisa y lo descarga".

Los responsables de los archivos de los medios encuestados coinciden en destacar que la digitalización de sus empresas garantiza un acceso universal, abierto a todos los usuarios de la redacción. Según su valoración, los sistemas digitales favorecen el ahorro de espacio, tiempo y dinero.

\section{"En televisión, el documentalista puede considerarse coproductor de informaciones en este entorno por su trabajo de organización, almacenamiento y apoyo al periodista"}

Con anterioridad, el periodista se quejaba de la falta de tiempo para acudir al archivo. Ahora, puede utilizar el material de documentación más a menudo. La digitalización e integración de las redacciones facilita el acceso directo a las imágenes disponibles y no sólo a los metadatos.

El documentalista puede considerarse coproductor de informaciones en este entorno por su trabajo de organización, almacenamiento y apoyo al periodista. Un subdirector de Informativos de Telemadrid destaca: "Los documentalistas procuran que el material disponible en el servidor central sea lo que interesa, y que eliminen lo que no interesa. El documentalista se convierte en el gestor del material útil, tanto en anticipo como en retraso. Además de sacarle un gran partido al material, hace que el sistema genere satisfacción entre los periodistas".

El uso inteligente del archivo constituye por sí solo el origen de un buen número de informaciones y en muchos casos, enriquece notablemente las piezas de actualidad, al ligarlas a su contexto. Por ejemplo, al preparar una información sobre la retirada de un futbolista, mediante un solo clic en su ordenador puede acceder y ver todas las imágenes de ese futbolista que están disponibles en el archivo e incorporar las que mejor se ajusten a la historia que desea contar. Ello indudablemente ayuda, al menos sobre el papel, a mejorar su trabajo.

\subsection{Archivos escritos: internet como sustitutivo}

En contraste con los archivos audiovisuales, los escritos se encuentran en una situación más delicada. El aumento de la autonomía de los periodistas, la facilidad 
de uso de las bases de datos y, sobre todo, la irrupción de internet lo explicaría.

Las consultas en los centros de documentación han descendido según reflejan los resultados de la encuesta. Los redactores suelen entrar en la Red para buscar datos de background y para localizar información muy concreta. Internet es ya un recurso de primera magnitud, con frecuencia, exclusivo. Las consultas al centro de documentación se reducen en estas circunstancias. Algunos reporteros admiten que únicamente delegan las búsquedas en los documentalistas cuando el tiempo apremia, para trabajar en otros asuntos mientras tanto.

\section{"En contraste con los archivos audiovisuales, los escritos se encuentran en una situación más delicada"}

En nueve de los diarios estudiados, el volumen de peticiones de información ha disminuido tras la digitalización del archivo. En uno de estos medios, las solicitudes se han especializado, dado que son "mucho más precisas, más concretas". Otro encuestado indica que las consultas triviales "prácticamente han desaparecido". Lo mismo ocurre en los centros de documentación de las televisiones, donde las demandas de información escrita han descendido o se han mantenido, si bien las peticiones de información audiovisual se han incrementado.

Así pues, mientras el número de consultas a los servicios de documentación escrita disminuyen, como lo confirman también Aguilar y Renedo (2007), el uso de buscadores y particularmente de hemerotecas accesibles por internet se ha generalizado, convirtiéndose en fuentes recurrentes, hasta el extremo de sustituir en algunos casos al uso de la base de datos del propio medio. En Catalunya Ràdio y Televisió de Catalunya se observó como, a pesar de que sus respectivos centros de documentación elaboran una excelente base de datos, los redactores preferían la consulta de hemerotecas digitales disponibles en internet, como las de la $B B C$ o $E l$ mundo, mientras reconocían lacónicamente que no tenían "la costumbre [de utilizar la base de su centro de documentación]". La responsable del servicio en Televisió de Catalunya lamentaba que la inversión destinada a la digitalización del archivo textual no hubiese obtenido el éxito esperado en cuanto al número de consultas directas. En la cobertura diaria, los centros de documentación apenas pueden competir con la agilidad, la inmediatez y la aparente sencillez de internet.

\section{Periodistas e internet... y sobre todo Google}

En general, los periodistas reconocen disponer de unos conocimientos limitados sobre búsqueda de información en entornos digitales, aunque con frecuencia no dudan en afirmar que son suficientes para satisfacer sus necesidades más habituales. Algunos aducen que se precisa demasiado tiempo de aprendizaje para dominar técnicas avanzadas de búsqueda en la Red. Un tiempo del que no disponen.

La falta de formación es uno de los grandes inconvenientes para los redactores, ya que esta tarea nunca ha sido prioritaria para las empresas. Palomo (2002) revela que sólo un $31,2 \%$ de los periódicos del país ofrecieron cursos de formación sobre el uso de la Red a sus trabajadores. Los redactores asumieron el trabajo en internet sin la formación necesaria y de manera autodidacta (Masip, 2008). El motivo hay que buscarlo en la forma en que internet se introdujo en las redacciones del país, sin una planificación y vinculado a actualizaciones tecnológicas de mucho más calado. Los datos proporcionados por los documentalistas encuestados lo confirman. Así, 18 de los 25 medios realizaron sesiones formativas sobre el uso del archivo digitalizado; aunque sólo en tres medios se consideró oportuno formar a los periodistas en el uso de la Red.

La falta de formación ha tenido consecuencias tanto en la función del documentalista en la redacción, como en la calidad de los productos periodísticos. La escasa fiabilidad de muchas fuentes obligaría al periodista a extremar las precauciones y contrastar, aún más, la información. Sin embargo, ante la premura en el cierre de las ediciones, algunos confiesan no hacerlo.

Lo más habitual para localizar información en la Red es recurrir a los buscadores. Google es el motor preferido por los periodistas. En 2005, lo usaba el $38,4 \%$ de los periodistas catalanes, seguido a mucha distancia de Yahoo! y Altavista (Masip, 2005). La rapidez es la ventaja más valorada: un $31,5 \%$ de los periodistas encuestados considera que ésta debería ser la propiedad principal en un buscador. A continuación se sitúa la exactitud de los resultados obtenidos. Es decir, un aspecto técnico está por delante de la calidad. Al igual que en otros estudios (Garrison, 2002), el uso de las opciones de búsqueda avanzada es mínimo; un $40 \%$ no las emplea nunca o casi nunca, y sólo un $13,2 \%$ las utiliza siempre. Las opciones más comunes son los operadores booleanos $(41,3 \%)$, la búsqueda por frase exacta $(31,9 \%)$ y la limitación por campos $(27,2 \%)$. Entre los documentalistas, el predominio de Google resulta avasallador y alcanza un $88 \%$, según Guallar y Cornet (2005). 


\section{Crisis de las funciones tradicionales de los documentalistas}

La digitalización de las redacciones ha cambiado por completo los centros de documentación y sus profesionales han tenido que afrontar nuevos problemas. $\mathrm{Al}$ atávico abandono que han padecido los centros de documentación (Fuentes, 1994), que se ha traducido, por ejemplo, en una falta de equipamientos, de personal, o en ser el último reducto en adoptar ciertas tecnologías, hay que añadir un deterioro de la percepción que muchos redactores tienen de dichos centros.

En algunos círculos profesionales existe la sensación de que los centros de documentación son superfluos, a causa de la pujanza de internet, que proporciona gran cantidad de datos gratuitamente. Hay pocos cibermedios que posean centro de documentación propio, y todavía menos que tengan al frente a un documentalista. El problema se agrava cuando los periodistas asumen labores de documentalista y acaban creyendo que pueden prescindir de sus servicios.

\section{"En algunos círculos profesionales existe la sensación de que los centros de documentación son superfluos, a causa de la pujanza de internet"}

Los documentalistas se convierten en profesionales "transparentes" para muchos periodistas. Sirva de ejemplo el caso observado en La vanguardia, donde los reporteros valoran positivamente su centro de documentación y se muestran orgullosos tanto de su hemeroteca centenaria como de su histórico fondo fotográfico. No obstante, se observa que el centro de documentación está aquejado de un agudo problema de visibilidad. Los periodistas consultan ampliamente la base de datos del rotativo del Grupo Godó, Aurora. El acceso es directo desde el programa Hermes, lo cual posibilita trabajar simultáneamente en la redacción del texto y en la búsqueda documental, así como la integración automática de fotografías. Las consultas son constantes, pero los periodistas no asocian la información obtenida mediante Aurora a la labor de los documentalistas. La mayoría distingue entre la intranet (Aurora) y el centro de documentación y los considera servicios diferentes. Cuando un redactor se refiere al servicio de documentación, piensa exclusivamente en el espacio físico que ocupa y en las consultas directas; lo desvincula de Aurora, como si éste no fuera producto de la labor de los documentalistas.

A los problemas de visibilidad, debe añadírsele otro inconveniente, como es el desconocimiento entre ciertos periodistas del perfil real de los documentalistas y de su función de apoyo a los redactores, manteniéndose una visión reduccionista del documentalista como mero organizador y guardián del archivo. Lo ilustra el caso de un periodista de la sección de Economía de un periódico que al referirse a los documentalistas echaba de menos "un profesional capaz de realizar tareas de búsqueda documental, propias del periodismo de investigación".

Como hemos apuntado, en opinión de los responsables de documentación, las peticiones al servicio han disminuido. Está percepción es compartida por los propios redactores, que reconocen que prefieren la autonomía que les proporciona internet. De hecho, en 2004, un 76,1\% de los periodistas catalanes consultaba internet diariamente, mientras que sólo un $28,9 \%$ accedía al centro de documentación con la misma asiduidad (Masip, 2005). Además, hasta un 50\% estaba bastante o muy de acuerdo con la idea de que la Red acabará por sustituir los centros de documentación.

Sin embargo, los documentalistas encuestados no comparten esta posición. Un 70\% de los responsables de los archivos de prensa considera que los periodistas prefieren buscar información textual en sus unidades antes que hacerlo en internet. Afirmación que sorprende ya que ellos mismos reconocen el descenso en el número de consultas. Los documentalistas que ejercen en televisión, en cambio, discrepan y hasta un $67 \%$ afirma que la Red prevalece.

La situación es diametralmente opuesta por lo que se refiere a la información audiovisual. El 87\% de los jefes de documentación encuestados coinciden en afirmar que el servicio de archivo es el preferido por encima de la Red. Y es que, efectivamente, la recuperación de información audiovisual en internet ha afectado a las redacciones televisivas, aunque de forma diferente a lo ocurrido con los datos de naturaleza textual. El intercambio de vídeo y audio por la red -aunque aún no tengan calidad broadcast- funciona como una fuente de información que complementa la tarea redaccional. Los periodistas entran en internet para ampliar datos, contactar con afectados o expertos e incluir material gráfico. Pero casi siempre esa información tiene un carácter subsidiario respecto de las imágenes del propio medio y de las suministradas por agencias. Algunos redactores, además, sostienen que internet puede plantear problemas para verificar su origen.

\section{Nuevos roles de periodistas y documentalistas}

La responsabilidad de los periodistas sobre el producto final se ha incrementado. Los redactores no dependen como antes de otros profesionales y servicios, incluyendo a los documentalistas y los centros de 
documentación. En opinión de los documentalistas, la digitalización de los fondos hace que mejore la capacidad de los periodistas para producir informaciones. Así opina un $72 \%$ de los encuestados. Los periodistas, no obstante, sin dejar de reconocer las ventajas de la digitalización, no dudan en afirmar que en ocasiones, ante la necesidad de acumular diversas tareas, la calidad de sus productos se resiente. Y es que tener más autonomía no equivale necesariamente a la mejora de las informaciones.

Las innovaciones tecnológicas han propiciado que los periodistas acumulen más tareas, por lo que se han visto obligados a desarrollar o perfeccionar nuevas habilidades. Además de cubrir un acontecimiento de interés, muchos de ellos tienen que sacar fotos -lo hemos visto en el Diari de Girona- o grabar vídeos -por ejemplo en la Agència Catalana de Notícies- y, al llegar a la redacción, montar las piezas -algo común en la mayoría de televisiones-, buscar documentación, etc. El resultado de combinar una formación incompleta y la presión en los plazos es claro: muchas tareas se efectúan de manera deficiente, y diversos responsables de televisiones y periódicos lo reconocen.

Conviene preguntarse por tanto qué papel juegan los documentalistas en el engranaje de una maquinaria en la que su trabajo está limitado y donde disminuye -o incluso desaparece- su faceta creativa. Varios profesionales sostienen que las redacciones digitalizadas refuerzan el individualismo y reducen las oportunidades de intercambio de información entre periodistas y documentalistas.

\section{"El tiempo que los documentalistas ahorran en la búsqueda de información para los redactores lo emplean en labores que se podrían tildar de clásicas"}

Cabe destacar que la mayoría de los documentalistas que respondieron la encuesta, no comparten la opinión de que los periodistas estén asumiendo labores tradicionalmente consideradas propias del documentalista. En la misma línea, tampoco consideran que su perfil profesional esté en peligro, ni vaciado de contenido, aunque reconocen que la digitalización y la disminución de las peticiones de información han modificado sus funciones (64\%). Sin embargo, a partir de sus respuestas, se comprueba que el tiempo que ahorran en la búsqueda de información para los redactores lo emplean en labores que se podrían tildar de clásicas, como "efectuar un análisis documental más detallado para mejorar la recuperación de datos por parte de los periodistas" o "incorporar materiales al fondo", dos funciones que ocupan entre el $31 \mathrm{y}$ el $40 \%$ del tiempo ahorrado en los medios escritos. En cambio, otras labores como "asumir tareas periodísticas, preparando piezas con información de archivo o de otras fuentes" o "recuperar información sobre determinados temas para comercializarla", se benefician todavía de pocas horas, en torno al 20 y el $15 \%$ del tiempo ganado. Existen excepciones, como en La Voz o La Razón donde, según sus responsables, en torno al $40 \%$ del tiempo ahorrado como consecuencia del descenso de peticiones de los redactores lo destinan a labores periodísticas.

\section{Conclusiones}

Como sucedió con el uso de otras tecnologías, la digitalización de los servicios de documentación generó una ola de optimismo sobre las potencialidades del nuevo sistema. La fascinación por el modo en que se había aplicado en Estados Unidos contagió a los directivos españoles. Sin embargo, ambos países no partían de la misma situación. Ni se afrontaban necesidades similares, ni gozaban de la misma tradición, ni se dirigían a profesionales con idéntica formación.

El tiempo ha demostrado que la digitalización del servicio de documentación ha permitido mejorar el trabajo de los periodistas e incrementar la calidad de algunas piezas, sobre todo cuando se trata de la recuperación de archivos audiovisuales. No obstante, la Red ha eclipsado muchos de los logros de los archivos. En los últimos años los redactores han optado por internet como primera (y a veces única) fuente para obtener recursos, sobre todo escritos.

Esta circunstancia, junto con los problemas de visibilidad, debería poner en alerta a los responsables de los archivos de prensa. Coincidimos con López-deQuintana (2007) en que "el archivo terminará siendo un concepto abstracto de accesibilidad", pero no hay motivos para el entusiasmo, como parece desprenderse de algunas impresiones de los jefes de documentación, que mantienen el mismo optimismo que cuando se enteraron de que su área iba a ser automatizada. Algunos directivos entrevistados hablan abiertamente de la posibilidad de externalizar el servicio.

También se plantea una segunda paradoja, esta vez relacionada con los periodistas. El hecho de que los re-

\section{"En los últimos años los redactores han optado por internet como primera (y a veces única) fuente para obtener recursos, sobre todo escritos"}


dactores tengan que asumir más tareas del proceso de producción, entre ellas la de documentación, les confiere un mayor dominio sobre el producto final. Pero tras descubrir que nadie ha formado específicamente a un porcentaje notable de estos periodistas, se constata que la calidad de las informaciones no sólo no mejora, sino que tiende a empeorar.

Por último, cabe señalar que la digitalización abre nuevas oportunidades para los documentalistas como profesionales que colaboran estrechamente con los periodistas poniendo en práctica sus habilidades en la búsqueda y recuperación de informaciones complejas, y como potenciales creadores de contenidos.

\section{Notas}

1. Pese a que en el artículo las opiniones se atribuyen directamente a quien las formula, en algunos casos no ha sido posible hacerlo así por compromisos de confidencialidad.

\section{Bibliografía}

Agirreazaldegi, Teresa. "Claves y retos de la documentación digital en televisión”. El profesional de la información, 2007, v. 16, n. 5, pp. 433-442.

Aguilar-Gutierres, Manuel; Renedo, José-Ángel. "La difusión de los servicios de documentación escrita de TVE frente al alcance de Google: problemas y soluciones" En: IX Jornadas de gestión de la información. Influir y difundir: servicios documentales y comunicación. Madrid: Sedic, 2007, pp. 39-45.

De Bustos, Pilar. "Sistemas integrados y gestión documental. La experiencia de Telecinco". El profesional de la información, 2007, v. 16, n. 5, pp. 450-455.

Fuentes, M. Eulàlia. "Evolució de la documentació periodística a Espanya durant els darrers cinc anys i algunes experiència europees". L'experiència multimèdia. València: Generalitat Valenciana, 1994, pp. 17-28.

García-Avilés, José-Alberto, El periodismo audiovisual ante la convergencia digital. Elche: Universidad Miguel Hernández, 2006.

García-Avilés, José-Alberto; León, Bienvenido. "Journalistic Practice in Digital Television Newsrooms. The Case of Spain's Tele 5 and Antena 3". Journalism. 2002, v. 3, n. 3, pp. 355-371.

Garrison, Bruce. "Journalists' Perceptions of Online Information-Gathering Problems". Journalism \& Mass Communication Quarterly 2002, v. 77, n. 3 , p. $500-514$.

Giménez, Elea. "Periodista y documentalista ¿Dos o uno?” En: IV Congreso Nacional de Periodismo Digital. Huesca, enero de 2003.

http://cuarto.congresoperiodismo.com/ediciones_ant/1_congreso/viernes. html

Guallar, Javier; Cornet, Anna. "Fuentes de información digitales en centros de documentación de prensa: las bases de datos comerciales". El profesional de la información, 2004, v. 13, n. 2, pp. 107-117.

http://eprints.rclis.org/7858/1/epimar04_guallar-cornet_fuentes1.pdf

Guallar, Javier; Cornet, Anna. "Fuentes de información digitales en centros de documentación de prensa: recursos web gratuitos". El profesional de la información, 2005, v. 14, n. 4, pp. 296-309.

http://eprints.rclis.org/8003/1/epijul05_guallar-cornet_fuentes2.pdf
Hidalgo, Paloma. "La documentación audiovisual en las televisiones. La problemática actual y el reto de la digitalización" Documentación de las ciencias de la información, 2005, v. 28, pp. 159-171.

López-de-Quintana, Eugenio. "Transición y tendencias de la documentación en televisión: digitalización y nuevo mercado audiovisual". El profesional de la información, 2007, v. 16, n. 5, pp. 397-408.

Martín, Javier; López-Pavillard, Jacobo. "RTVE: Reorganización de la Documentación en un entorno multimedia" Cuadernos de documentación multimedia, 1999, n. 6-7.

http://www.ucm.es/info/multidoc/multidoc/revista/cuad6-7/rne.htm

Masip, Pere. Internet a les redaccions. Barcelona: Trípodos, 2008.

Masip, Pere. Presencia i ús d'internet a les redaccions. Periodistes, rutines professionals i tecnologia. Barcelona: Universitat Ramon Llull, 2005. Tesis doctoral.

Micó, Josep-Lluís. Teleperiodisme digital. Trípodos: Barcelona, 2006.

Micó, Josep-Lluís. La edición digital no lineal en los programas informativos de televisión. València. Universitat Politècnica de València, 2003. Tesis doctoral.

Palomo, Bella. El uso redaccional de internet en la prensa diaria española. Màlaga: Universidad de Málaga, 2002. Tesis doctoral.

Paul, Nora. "Media Libraries and New Media". Netmedia97. Londres: City University, 1997, pp. 1-4.

Rintala, Niina; Suolanen, Sanna. "The implications of digitalization for job descriptions, competencies and the quality of working life". Nordicom Review, 2005, n. 2.

http://www.nordicon.gu.se/common/publ_pdf/222_rintala_suolanen.pdf

Risoto, Josefa. "Gestión de la documentación audiovisual en Televisión Valenciana". Hipertext.net, 2004, n. 2.

http://www.hipertext.net

Rubio-Lacoba, María. "Seis reflexiones sobre la documentación en la Sociedad del Conocimiento". Información pública , 2004, v. 2, n. 2, pp. 107-122.

Rubio-Lacoba, María. "Nuevos tiempos para la documentación informativa en el periodismo digital: viejas y nuevas funciones del servicio de documentación digital”. Comunicación y sociedad, 2005, v. 18, n. 1, pp. 153-170.

Trillo-Dominguez, Magdalena; Moya-Anegón, Félix. "El profesional de la información en la era digital: el perfil del periodista-documentalista" En: Flores, Jesús; Cebrián-Herreros, Mariano; Esteve-Ramírez, Francisco (eds.). Blogalaxia y periodismo en la Red. Estudios, análisis y reflexiones. Madrid: Fragua, 2008. pp. 347-358.

\section{Josep-Lluís Micó-Sanz y Pere Masip-Masip}

DigiLab. Facultat de Comunicació Blanquerna. Universitat Ramon Llull, C/Valdonzella,23, 08001 Barcelona.

joseplluisms@blanquerna.url.edu

peremm@blanquerna.url.edu

José-Alberto García-Avilés.

Universidad Miguel Hernández. Ed. Torreblanca, Avda de la Universidad, $s / n, 03202$ Elche (Alicante).

jose.garciaa@umh.es

http://elnautilus.wordpress.com/ 